\title{
Good agreements between self and clinician-collected specimens for the detection of human papillomavirus in Brazilian patients
}

\author{
Karla Lopes Mandu de Campos' ${ }^{1}$ Ana Paula Machado', Flávia Gatto de Almeida', \\ Camila Mareti Bonin', Thiago Theodoro Martins Prata', Larissa Zatorre Almeida', \\ Cacilda Tezelli Junqueira Padovani', Alda Maria Teixeira Ferreira', \\ Carlos Eurico dos Santos Fernandes ${ }^{1}$, Inês Aparecida Tozetti²/+
}

'Laboratório de Imunologia e Biologia Molecular de Vírus, Centro de Ciências Biológicas e da Saúde ²Programa de Pós-Graduação em
Doenças Infecciosas e Parasitárias, Faculdade de Medicina, Universidade Federal de Mato Grosso do Sul, Campo Grande, MS, Brasil

Women infected with human papillomavirus (HPV) are at a higher risk of developing cervical lesions. In the current study, self and clinician-collected vaginal and cervical samples from women were processed to detect HPV DNA using polymerase chain reaction (PCR) with PGMY09/11 primers. HPV genotypes were determined using type-specific PCR. $H P V D N A$ detection showed good concordance between self and clinician-collected samples (84.6\%; kappa $=0.72)$. $H P V$ infection was found in $30 \%$ women and genotyping was more concordant among high-risk HPV (HR-HPV) than low-risk HPV (HR-HPV). HPV16 was the most frequently detected among the HR-HPV types. LR-HPV was detected at a higher frequency in self-collected; however, HR-HPV types were more frequently identified in clinician-collected samples than in self-collected samples. HPV infections of multiple types were detected in $20.5 \%$ of clinician-collected samples and $15.5 \%$ of self-collected samples. In this study, we demonstrated that the HPV DNA detection rate in selfcollected samples has good agreement with that of clinician-collected samples. Self-collected sampling, as a primary prevention strategy in countries with few resources, could be effective for identifying cases of HR-HPV, being more acceptable. The use of this method would enhance the coverage of screening programs for cervical cancer.

Key words: human papillomavirus - self-collected - clinician-collected - PCR

Women infected with human papillomavirus (HPV) are at a higher risk of developing cervical lesions than those without HPV infection (Koutsky et al. 1992). Epidemiological studies have shown that HPV has a causal role in the aetiology of cervical cancer (IARC 2007). In South and Central America, screening programs for cervical cancer have poor diagnostic quality and allow for only limited access to treatment; consequently, cervical cancer rates there are the highest in the world (Kitchener et al. 2006).

The need for repetitive testing and multiple clinic visits diminish the value of preventive cytological examinations in developing countries. Reductions in cervical cancer-related mortality through screening efforts are dependent on population-level coverage (Sowjanya et al. 2009). It is clear that HPV DNA testing is more costeffective than cytological methods and is also highly recommended as a substitute or combined method with Pap smears to detect HPV infection in high-grade cervical lesions (Lee et al. 2004, Chow et al. 2010).

Self-collected sampling for HPV DNA may be a new alternative collection method since its use can identify more women who are at risk for cervical cancer, especial-

doi: $10.1590 / 0074-0276130397$

Financial support: Fundect-MS, CNPq, CAPES

+ Corresponding author: inestozetti1408@hotmail.com

Received 12 August 2013

Accepted 13 February 2014 ly those who have no access to healthcare or are resistant to gynaecological examinations (Lack et al. 2005).

The meta-analysis conducted in 2007 verified the accuracy of self and clinician-collected sampling to identify women with genital HPV infections and showed that the two methods had equivalent abilities to detect HPV DNA (Petignat et al. 2007). Self-collected sampling has higher acceptability, suggesting that it is likely to have greater population coverage (Safaeian et al. 2007). Therefore, the present study aimed to evaluate the HPV DNA detection and genotyping concordance between self and clinician-collected cervicovaginal and cervical samples.

\section{SUBJECTS, MATERIALS AND METHODS}

Study population and sampling - This study was conducted between August-December 2011 and the women were recruited from Central Laboratory Municipal Campo Grande, state of Mato Grosso do Sul, Brazil, when they were forwarded to gynaecological exams in the public health system. Women were eligible to participate if they were $\geq 18$ years of age and had not undergone a hysterectomy. A total of 171 women provided written informed consent and completed the questionnaire at the time of enrollment. Participating women underwent two interventions for HPV DNA detection: with verbal and diagrammatic instruction, they self-collected a vaginal specimen; afterward, a health professional used a speculum and collected an endocervical specimen.

DNA isolation and HPV testing - The endocervical and vaginal DNA were extracted using a Wizard $^{\circledR}$ Ge- 
nomic DNA Purification Kit (Promega, Corporation, Madison, WI, USA). HPV DNA detection was performed by polymerase chain reaction (PCR) amplification with the use of the PGMY09/11 primers (Gravitt et al. 2000). The human $\beta$-globin gene was co-amplified with $\mathrm{PC} 04 / \mathrm{GH} 20$ primers. All $\beta$-globin negative samples were excluded from the analysis. Samples that amplified the PGMY09/11 primers were genotyped by type-specific PCR using primers for high-risk HPV (HR-HPV), HPV16, 18, 31, 33, 45 (Guo et al. 2007) and low-risk HPV (LR-HPV), HPV6, 11 (Silva et al. 2003). The PCR products were analysed using $1.5 \%$ agarose gel electrophoresis with ethidium bromide staining to visualise the DNA under ultraviolet light. Molecular weights were determined by comparison with a 100-bp DNA ladder.

Statistical analysis - Agreement between the self and clinician-collected samples was measured using kappa (к) statistics. The chi-square test was used to analyse frequency data obtained on the questionnaire. The significance level was set at 0.05 . All analyses were performed using SPSS 10.0 software and BioEstat 5.0.

\section{RESULTS}

Of the samples collected from the 170 participants, only one was excluded because $\beta$-globin could not be amplified. A total of $30 \%(51 / 170)$ of the samples were HPV DNA-positive. The women in this study were 1865 years of age (median, 35 years), while the average age at first sexual intercourse was 17 years (range, 11-30 years). We found a lower frequency of HPV infection in women $\geq 30$ years $(p=0.009)$.

HPV tests results showed that there was $84.6 \%$ concordance between the self and clinician-collected samples $(\kappa=0.72)$, which indicates good agreement. Six women tested HPV-positive on clinician-collected samples, but HPV-negative on self-collected samples. Twelve women tested HPV-positive on self-collected samples (Table I). HPV of any type was detected in $22.9 \%(39 / 170)$ of the clinician-collected samples and $26.5 \%(45 / 170)$ of the self-collected samples.

HPV16, the most frequently detected HR-HPV type, was present in six samples obtained by both methods. The specific HPV types identified in the self and clinician-collected samples are shown in Table II.

LR-HPV types were detected at a higher frequency in the self-collected samples than in the clinician-collected samples $(23.5 \%$ and $15.7 \%$, respectively; $\mathrm{p}=0.78)$. How- ever, HR-HPV types were identified more frequently in the clinician-collected samples than in the self-collected samples $(33.3 \%$ and $27.4 \%$, respectively; $p=0.55)$. The concordance of the specific HPV type results between the collection methods demonstrated that $27.4 \%$ of the samples had complete agreement for HR-HPV types and $13.7 \%$ had complete agreement for LR-HPV types (Table III).

HPV infection with multiple types was detected in $20.5 \%(8 / 51)$ of the clinician-collected samples and $15.5 \%$ $(7 / 51)$ of the self-collected samples. One sample tested positive for HPV16, 18, 31, 6 and 11 using both methods.

\section{DISCUSSION}

Herein, we evaluated the HPV DNA detection agreement between self and clinician-collected samples. Studies have found that the use of self-collected samples can enable the identification of the HPV types that infect the cervix (Gravitt et al. 2001, Brink et al. 2006). Our results demonstrated that self-collection sampling generates comparable amounts of material for HPV testing to those of clinician samples (both amplified $99.4 \%$ of the $\beta$-globin gene). Moreover, the concordance between the methods was satisfactory $(84.6 \%, \kappa=0.72)$. Studies reported a concordance of $87 \%$ between the two methods (Brink et al. 2006). A recent study showed agreement $(93 \%$; 0.849$)$ between self-sampling and the reference smears in regards

\section{TABLE II}

Specific human papillomavirus (HPV) types detected by self and clinician-collected

\begin{tabular}{lcc}
\hline $\begin{array}{l}\text { HPV types } \\
(\mathrm{n})\end{array}$ & $\begin{array}{c}\text { Clinician-collected } \\
\mathrm{n}(\%)\end{array}$ & $\begin{array}{c}\text { Self-collected } \\
\mathrm{n}(\%)\end{array}$ \\
\hline $\begin{array}{l}\text { High-risk } \\
45\end{array}$ & $3(7.7)$ & $3(6.7)$ \\
18 & $4(10.2)$ & $3(6.7)$ \\
31 & $4(10.2)$ & $4(8.9)$ \\
33 & $5(12.8)$ & $3(6.7)$ \\
16 & $6(15.4)$ & $6(13.3)$ \\
Low-risk & & $12(26.7)$ \\
$6 / 11$ & $8(20.6)$ & $14(31)$ \\
Undetermined & $9(23.1)$ & $45(100)$ \\
\hline Total & $39(100)$ & \\
\hline
\end{tabular}

TABLE I

Concordance between human papillomavirus (HPV) DNA detected by self and clinician-collected

\begin{tabular}{lcccccc}
\hline & \multicolumn{2}{c}{$\begin{array}{c}\text { Self-collected } \\
\mathrm{n}(\%)\end{array}$} & & Total \\
Clinician-collected & Negative & Positive & & kappa $(\%)$ & $\begin{array}{c}\text { Concordance }^{a} \\
(\%)\end{array}$ \\
\cline { 2 - 5 } Negative & $119(70)$ & $12(7.1)$ & & $131(77.1)$ & - & 0.84 \\
Positive & $6(3.5)$ & $33(19.4)$ & & $39(22.9)$ & 0.72 & - \\
\hline Total & $125(73.5)$ & $45(26.5)$ & & $170(100)$ & - & - \\
\hline
\end{tabular}

$a$ : concordance between methods. 
to HR-HPV detected by real-time PCR with a modified GP5+/6+ primer mix (Jentschke et al. 2013).

One explanation for the high concordance is that the self-collected specimens represent an admixture of vaginal and cervical cells and the sampling order (self-collection first) may increase the number of positive samples owing to a higher number of exfoliated cells (Gravitt et al. 2001, Castle et al. 2007). In addition, HPV testing using PGMY09/11 primers has higher HPV DNA detection accuracy than other tests (Bhatla \& Moda 2009).

Similarly, we found that the frequencies of HPV DNA detection in self and clinician-collected samples were similar (26.5\% vs. $22.9 \%$, respectively) and that HPV infection could be detected in both the vaginal and endocervical epithelia. HR-HPV types were well detected in both methods and the concordance between the methods was higher for the detection of HR-HPV DNA than that for that of LR-HPV.

The hypothesis that sample self-collection may be suitable as a novel method of cervical cancer screening by molecular tests was supported by other studies (Jentschke et al. 2013, Lorenzi et al. 2013), whereas the same is not true for Pap smears. Conversely, in a systematic review, Racey et al. (2013) recently reported that the positive predictive value of this test decreased when the sample was self-collected, with better predictive outcomes associated with high-grade lesions.

Lorenzi et al. (2013) detected a positive rate of 12.3\% for HR-HPV using care HPVTM (QIAGEN, USA) for detection in self and professionally collected samples. These authors also observed a slightly higher frequency of HR-HPV positive results in the self-sampling group than in the professionally sampled group $(13.5 \%$ vs. $11 \%$, respectively), although the results obtained by other authors (Castle et al. 2007, Petignat et al. 2007).

In the present study, women were recruited from the public health system after they were referred to a gynaecologist and this may explain the high positive rate of HPV DNA (30\%) in our samples.

The type of test used in the analysis of HPV DNA is another relevant variable to consider when determining the efficiency of both collection methods. The more sensitive the detection method, smaller the amount of sample required for successful detection (de Sanjosé et al. 2007). Another factor to consider is the type of instrument used to collect the cells (liquid-based, swab or endocervical cytobrush), which may affect the amount of sample collected (Lorenzato et al. 2002).
Compared to other HPV types, HPV16 and HPV18 confer a higher risk of cervical cancer (Koutsky et al. 1992). In the present study, HR-HPV16 was the most frequently detected type in both the self and clinician-collected samples and thus, self-collected samples show promise as an alternative diagnostic tool, as well as for epidemiologic studies and vaccine trials. The type-specific primers used in this study are considered the most prevalent viral types worldwide (Walboomers et al. 1999).

Regarding HPV types obtained from different samples, the detection of high-risk oncogenic HPV was more common in the clinical collection group. A study comparing the detection of HPV types in samples of cervical and vaginal origin found that low-risk oncogenic HPV was more prevalent in the vaginal epithelium. Hence, it is likely that the oncogenic HPV types have different survival mechanisms and viral production compared to LR-HPV types, which rarely produce cytological abnormalities and prefer to infect cells in the vagina, where the tissue is keratinised (Castle et al. 2007).

This fact may be associated with the restricted choice using only the primers to LR-HPV6 and 11 types.

In addition to oncogenic HPV, we verified that sample self-collection has the potential to detect multiple HPV infections. It is remarkable that infections with multiple HPV types were frequently found in a study of Brazilian women (Tozetti et al. 2006). Multiple HPV infections increase a woman's risk of developing cervical neoplasia, even if the co-infections is with an LR-HPV, since it could influence the development of low-grade squamous intraepithelial lesions (Trottier et al. 2006).

Another risk factor of HPV infection is age, as one study of sample self-collection by adolescents showed that HPV infection is more common in sexually active younger women (Silva et al. 2011), but that most cases are transient (Ho et al. 1998). In our study, we found lower frequency of infection in women $\geq 30$ years of age. These results were consistent with those of other studies (Lindell et al. 2002), that reported that HPV prevalence differs by age and is less common in women over age. It was suggested that screening using HPV-DNA tests is more appropriate in women $>30$ years of age since HPV infection is less likely to be transient in this age group unlike in younger women (Franco 2003).

HPV DNA testing has the potential to improve the efficacy of cervical cancer screening and is a more costeffective solution. Using this strategy, the screening interval can be extended to every three years compared to

TABLE III

Concordance between low-risk (LR) human papillomavirus (HPV) and high-risk (HR) HPV DNA detection in self and clinician-collected

\begin{tabular}{|c|c|c|c|c|c|c|c|}
\hline HPV & (n) & $\begin{array}{c}\text { Clinician }^{a} / \\
\text { self }^{a} \\
\mathrm{n}(\%)\end{array}$ & $\begin{array}{c}\text { Clinician }^{a} / \\
\text { self }^{b} \\
\mathrm{n}(\%)\end{array}$ & $\begin{array}{c}\text { Clinician }^{b} / \\
\text { self }^{a} \\
\text { n }(\%)\end{array}$ & $\begin{array}{c}\text { Clinician }^{b} / \\
\text { self }^{b} \\
\text { n (\%) }\end{array}$ & $\begin{array}{c}\text { Concordance } \\
(\%)\end{array}$ & kappa \\
\hline LR & 51 & 7 (13.7) & $1(1.9)$ & $5(9.8)$ & $38(74.5)$ & 88.2 & 0.6 \\
\hline HR & 51 & $14(27.4)$ & $3(5.9)$ & - & $34(66.7)$ & 94.1 & 0.9 \\
\hline
\end{tabular}

$a$ : positive; $b$ : negative; $c$ : concordance between methods. 
the use of annual Pap smears (Chow et al. 2010). Recognising this, women who are underserved in terms of cervical cancer screening, mainly those in remote areask of large countries such as Brazil, can justify the use of this self-collected method to the public health service.

In this study, we demonstrated that the results of theKo self-collected sampling method are in good agreement with those of the clinician-collected sampling method for the detection and typing of HPV DNA. Use of the self-collected sampling method as a primary prevention strategy in countries with few resources could effectively identify those women with HR-HPV. The self-collection method is better accepted among women; therefore, it could enhance cervical cancer screening program coverage and contribute significantly to reducing the incidence of cervical cancer.

\section{REFERENCES}

Bhatla N, Moda N 2009. The clinical utility of HPV DNA testing in cervical cancer screening strategies. Indian J Med Res 130: 261-265.

Brink AA, Meijer CJ, Wiegerinck MA, Nieboer TE, Kruitwagen RF, van Kemenade F, Daalmeijer NF, Hesselink AT, Berkhof J, Snijders PJ 2006. High concordance of results of testing for human papillomavirus in cervicovaginal samples collected by two methods with comparison of a novel self-sampling device to a conventional endocervical brush. J Clin Microbiol 44: 2518-2523.

Castle PE, Rodriguez AC, Porras C, Herrero R, Schiffman M, Gonzalez P, Hildesheim A, Burk RD 2007. A comparison of cervical and vaginal human papillomavirus. Sex Transm Dis 34: 849-855.

Chow IH, Tang CH, You SL, Liao CH, Chu TY, Chen CJ, Chen CA, Pwu RF 2010. Cost-effectiveness analysis of human papillomavirus DNA testing and Pap smear for cervical cancer screening in a publicly financed health-care system. Br J Cancer 103: 1773-1782.

de Sanjosé S, Diaz M, Castellsagué X, Clifford G, Bruni L, Muñoz N, Bosch FX 2007. Worldwide prevalence and genotypes distribution of cervical human papillomavirus DNA in women with normal cytology: a meta-analysis. Lancet Infect Dis 7: 453-459.

Franco EL 2003. Chapter 13: primary screening of cervical cancer with human papillomavirus tests. J Natl Cancer Inst Monogr 31: 89-96.

Gravitt PE, Lacey Jr JV, Brinton LA, Barnes WA, Kornegay JR, Greenberg MD, Greene SM, Hadjimichael OC, McGowan L, Mortel R, Schwartz PE, Zaino R, Hildesheim A 2001. Evaluations of self-collected cervicovaginal cell samples for human papillomavirus testing by polymerase chain reaction. Cancer Epidemiol Biomarkers Prev 10: 95-100.

Gravitt PE, Peyton CL, Alessi TQ, Wheeler CM, Coutlée F, S Hildesheim A, Schiffman MH, Scott DR, Apple RJ 2000. Improved amplification of genital human papillomaviruses. $J$ Clin Microbiol 38: 357-361.

Guo M, Sneige N, Silva EG, Jan YJ, Cogdell DE, Lin E, Luthra R, Zhang W 2007. Distribution and viral load of eight oncogenic types of human papillomavirus (HPV) and HPV 16 integration $_{\mathrm{T}}$ status in cervical intraepithelial neoplasia and carcinoma. Mod Pathol 20: 256-266.

Ho GY, Bierman R, Beardsley L, Chang CJ, Burk RD 1998. Natu-T ral history of cervicovaginal papillomavirus infection in young women. N Engl J Med 338: 423-428.

IARC - International Agency for Research on Cancer 2007. Monographs on the evaluation of carcinogenic risks to humans: human papillomaviruses, Vol. 90, WHO, Lyon, $670 \mathrm{pp}$.

Jentschke M, Soergel P, Hillemanns P 2013. Evaluation of a multiplex real time PCR assay for the detection of human papillomavirus infections on self-collected cervicovaginal lavage samples. $J \mathrm{Vi}$ rol Methods 193: 131-134.

chener HC, Castle PE, Cox JT 2006. Chapter 7: achievements and limitations of cervical cytology screening. Vaccine 24 (Suppl. 3): S63-S70.

outsky LA, Holmes KK, Critchlow CW, Stevens CE, Paavonen J, Beckmann AM, DeRouen TA, Galloway DA, Vernon D, Kiviat NB 1992. A cohort study of the risk of cervical intraepithelial neoplasia grade 2 or 3 in relation to papillomavirus infection. $N$ Engl J Med 327: 1272-1278.

ack N, West B, Jeffries D, Ekpo G, Morison L, Soutter WP, Walraven $\mathrm{G}$, Boryseiwicz $\mathrm{L}$ 2005. Comparison of non-invasive sampling methods for detection of HPV in rural African women. Sex Transm Infect 81: 239-241.

ee KJ, Lee JK, Saw HS 2004. Can human papillomavirus DNA testing substitute for cytology in the detection of high-grade cervical lesions? Arch Pathol Lab Med 128: 298-302.

Lindell M, Sanner K, Wikström I, Wilander E 2002. Self-sampling of vaginal fluid and high-risk human papillomavirus testing in women aged 50 years or older not attending Papanicolaou smear screening. BJOG 119: 245-248.

orenzato FR, Singer A, Ho L, Gesink D 2002. Human papillomavirus detection for cervical cancer prevention with polymerase chain reaction in self-collected samples. Am J Obstet Gynecol 186: 962-968.

Lorenzi AT, Freganani JH, Possati-Resende JC, Neto CS, Villa LL, Longatto-Filho A 2013. Self-collection for high-risk HPV detection in Brazilian women using the careHPVTM test. Gynecol Oncol 131: 131-134.

Petignat P, Faltin DL, Bruchim I, Tramèr MR, Franco EL, Coutlée F 2007. Are self-collected samples comparable to physician-collected cervical specimens for human papillomavirus DNA testing? Gynecol Oncol 105: 530-535.

Racey CS, Withrow DR, Gesink D 2013. Self-collected HPV testing improves participation in cervical cancer screening: a systematic review and meta-analysis. Can J Public Health 104: 159-166.

faeian M, Kiddugavu M, Gravitt PE, Ssekasanvu J, Murokora D, Sklar M, Serwadda D, Wawer MJ, Shah KV, Gray R 2007. Comparability of self-collected vaginal swabs and physician-collected cervical swabs for detection of human papillomavirus infections in Rakai, Uganda. Sex Transm Dis 34: 429-436.

Silva AMTC, Cruz AD, Silva CC, Borges FR, Curado MP 2003. Genotipagem de papiloma vírus humano em paciente com papilomatose laríngea recorrente. Rev Soc Bras Cancerol 49: 167-174.

lva J, Ribeiro J, Sousa H, Cerqueira F, Teixeira AL, Baldaque I, Osório T, Medeiros R 2011. Oncogenic HPV types infection in adolescents and university women from north Portugal: from self-sampling to cancer prevention. J Oncol 2011: 1-8.

owjanya AP, Paul P, Vedantham H, Ramakrishna G, Vidyadhari D, Vijayaraghavan K, Laksmi S, Sudula M, Ronnett BM, Das M, Shah KV, Gravitt PE 2009. Suitability of self-collected vaginal samples for cervical cancer screening in peri-urban villages in Andhra Pradesh, India. Cancer Epidemiol Biomarkers Prev 18: 1373-1378.

zetti IA, Scapulatempo IDL, Kawski VL, Ferreira AW, Levi JE 2006. Multiple types of human papillomavirus in women in Campo Grande, MS, Brazil. Braz J Infect Dis 10: 309-310.

rottier H, Mahmud S, Costa MC, Sobrinho JP, Duarte-Franco E, Rohan TE, Ferenczy A, Villa LL, Franco EL 2006. Human papillomavirus infections with multiple types and risk of cervical neoplasia. Cancer Epidemiol Biomarkers Prev 15: 1274-1280.

Walboomers JM, Jacobs MV, Manos MM, Bosch FX, Kummer JA, Shah KV, Snijders PJ, Peto J, Meijer CJ, Muñoz N 1999. Human papillomavirus is a necessary cause of invasive cervical cancer worldwide. J Pathol 189: 12-19. 